2015

\title{
Towards a Natural Law Foundationalist Theory of Universal Human Rights
}

Anthony Robert Sangiuliano

Follow this and additional works at: http:// digitalcommons.osgoode.yorku.ca/olsrps

Part of the Human Rights Law Commons, and the Legal Ethics and Professional Responsibility Commons

\section{Recommended Citation}

Sangiuliano, Anthony Robert, "Towards a Natural Law Foundationalist Theory of Universal Human Rights" (2015). Osgoode Legal Studies Research Paper Series. 111.

http://digitalcommons.osgoode.yorku.ca/olsrps/111 
Osgoode Legal Studies Research Paper No. 33

Vol. 11/ Issue. 07/ (2015)

\title{
Towards a Natural Law Foundationalist Theory of Universal Human Rights
}

Transnational Legal Theory, Vol. 5 (2), 2014.

Anthony Robert Sangiuliano

\begin{abstract}
:
The contemporary literature on the philosophy of human rights features a clash between two opposing theoretical paradigms. The first paradigm, called Functionalism, grounds the nature of human rights in their practical or political significance. The second paradigm, called Foundationalism, grounds the nature of human rights in a pre-political substratum of moral thought to which positive legal-political institutions ought to conform. What tends to make the first paradigm more appealing is that it avoids the problem of grounding human rights in moral considerations that may be ethnocentric and thus not acceptable to all peoples everywhere. This paper makes a case for a version of Foundationalism called Natural Law Foundationalism, which has often been overlooked in the contemporary literature. It argues that Natural Law Foundationalism is a promising view because it is capable of confronting the ethnocentricity problem more effectively than other versions of Foundationalism. It also argues that the view can deliver on its promise because its main tenets have sufficient philosophical defensibility.

\section{Keywords:}

Human Rights, International Legal Theory, John Finnis, Law and Ethics, Natural Law Theory

\section{Author(s):}

Anthony Robert Sangiuliano

Osgoode Hall Law School

E: ar.sangiuliano@gmail.com
\end{abstract}




\title{
Towards a Natural Law Foundationalist Theory of Universal Human Rights
}

\author{
Anthony Robert Sangiuliano*
}

\begin{abstract}
The contemporary literature on the philosophy of human rights features a clash between two opposing theoretical paradigms. The first paradigm, called Functionalism, grounds the nature of human rights in their practical or political significance. The second paradigm, called Foundationalism, grounds the nature of human rights in a pre-political substratum of moral thought to which positive legal-political institutions ought to conform. What tends to make the first paradigm more appealing is that it avoids the problem of grounding human rights in moral considerations that may be ethnocentric and thus not acceptable to all peoples everywhere. This paper makes a case for a version of Foundationalism called Natural Law Foundationalism, which has often been overlooked in the contemporary literature. It argues that Natural Law Foundationalism is a promising view because it is capable of confronting the ethnocentricity problem more effectively than other versions of Foundationalism. It also argues that the view can deliver on its promise because its main tenets have sufficient philosophical defensibility.
\end{abstract}

\section{INTRODUCTION}

Established by the Universal Declaration of Human Rights ${ }^{1}$ in 1948, the legal and political regime of universal human rights is a familiar and thriving practice within the global arena of state action. The high-priority norms it establishes help to protect people everywhere from abuses of state power. It is undoubtedly a complex phenomenon. As put by Rainer Forst, ${ }^{2}$ human rights have a moral dimension; they represent urgent moral con-

* JD Candidate (2015), Osgoode Hall Law School, York University, Canada. This article was originally written for Professor Brian Slattery's 2012-13 first-year Legal Theory Seminar on universal human rights at Osgoode Hall Law School. I would like to thank Professor Slattery for his amiable tutelage and poignant objections to earlier versions of the article. I would also like to thank Jessica Fleming and Ruth Massey for editorial assistance. The article was awarded the 2014 Osgoode Hall Law School JSD Torys Research and Writing Award.

1 Universal Declaration of Human Rights (adopted 10 December 1948) UNGA Res 217 A(III).

2 See Rainer Forst, 'The Justification of Human Rights and the Basic Right to Justification: A Reflexive Approach' (2010) 120 Ethics 711, 711-12. 
cerns that states must never ignore. They have a political dimension; they set standards of basic political legitimacy. They have a legal dimension; they are posited and enshrined in national constitutions and international treaties. They have a social dimension; they are asserted for the purposes of resisting oppression and exploitation. The study of universal human rights accordingly engages a variety of disciplines, incorporating perspectives from law, politics, sociology and anthropology.

This paper offers a contribution to the philosophical study of human rights. Ascertaining the domain of the philosophy of human rights is, unsurprisingly, a contested matter in itself. I shall take as a starting point the guiding proposition that the philosophy of human rights investigates the nature of a human right, or what kind of object a human right is within our broader system of normative thinking. This aim is distinct from that of, for example, charting the history of human rights theory or practice or exploring the social, legal or political motivations or ramifications of enacting positive instruments that codify human rights. These distinct aims may, of course, overlap with the project of investigating the nature of human rights. Our guiding proposition about the philosophy of human rights, however, is that it is concerned with the most general and abstract grounds of our thinking about the objects that we term 'human rights', as well as the criteria for the correct use of that term. ${ }^{3}$ It supports the distinct aims by shedding light on that object whose history, motivations and ramifications the distinct aims explore.

The contemporary philosophy of human rights literature features a clash between two opposing theoretical paradigms. Following John Tasioulas, I will call these paradigms Foundationalism and Functionalism. ${ }^{4}$ According to Foundationalism, the nature of a human right is specifiable by normative considerations that refer, not to the characteristics of any positive institutions purporting to codify human rights, but to characteristics that a person has simply in virtue of her humanity, that is, her human nature, or her status or dignity qua human being. On this view, a human right is not something that a person possesses as a result of her membership in any legal, political or social association. Instead, the grounds of human rights are found in a more foundational pre-political substratum of moral thought in terms of which positive institutions may be criticised. By contrast, Functionalism, whose initial advocate was John Rawls, ${ }^{5}$

3 For further discussion of a similar conception of the philosophy of human rights, see James Griffin, On Human Rights (Oxford University Press, 2008) 14-18. See also Charles R Beitz, The Idea of Human Rights (Oxford University Press, 2009) 11.

4 John Tasioulas, 'Towards a Philosophy of Human Rights' (2012) 65 Current Legal Problems 1, 6. Elsewhere, Tasioulas has called Foundationalism the 'orthodox conception of human rights'.: John Tasioulas, 'Are Human Rights Essentially Triggers for Intervention?' (2009) 4 Philosophy Compass 938, 938. Foundationalism has also been called Naturalism or Traditionalism: see Beitz (n 3) 49; Joseph Raz, 'Human Rights Without Foundations' in Samantha Besson and John Tasioulas (eds), The Philosophy of International Law (Oxford University Press, 2010) 321, 323. Functionalism has also been called the 'practical conception' of human rights, or the 'political conception': see Beitz (n 3) 102; Tasioulas, 'Triggers', ibid; Raz, ibid, 327.

5 John Rawls, The Law of Peoples (Harvard University Press, 1999) 78-82. 
takes the existing practice of the human rights regime as its point of departure. On this view, the nature of a human right is grounded in its functional role in regulating the conduct of political institutions within the legal-political practice of universal human rights, not in a more foundational, pre-political substratum of moral thought. A human right is an international norm or standard that gives certain reasons to actors in the global forum to behave in specified ways.

My goal in this essay is to make a case for a version of Foundationalism that I will call Natural Law Foundationalism. As the moniker suggests, this approach takes inspiration from the natural law tradition of Aristotle and Aquinas, as it has been developed more recently by the legal philosopher John Finnis. ${ }^{6}$ It interprets the Foundationalist claim that human rights are essentially linked to the notion of humanity by holding that the normative considerations which specify the grounds of human rights are universal human goods discoverable by the natural use of human practical reason. These goods constitute the foundational, pre-political substratum to which the positive legal-political universal human rights regime is answerable. Moreover, the view claims that natural human practical reason has self-evident epistemological access to the goods in question, which are universally knowable by all peoples.

Natural Law Foundationalism has been mentioned in passing amidst the contemporary clash between Foundationalism and Functionalism, but it is underdeveloped compared to what I will call Metaphysical Foundationalism. I intend to demonstrate that it deserves greater attention. This is because it promises to be able to confront the main Functionalist objection to Foundationalism-namely that Foundationalism's adumbration of the nature of a human right is fundamentally ethnocentric-more straightforwardly than Metaphysical Foundationalism. Furthermore, I intend to show that Natural Law Foundationalism is able to make good on its promise. This is because its central claims about human practical reason and the universal self-evidence of basic human goods have sufficient philosophical plausibility. In short, the thesis of this essay is that Natural Law Foundationalism is a legitimate participant in the contemporary clash between Foundationalism and Functionalism, and that the view should be taken more seriously as such.

I proceed as follows. In Part II, I explicate in greater detail the Functionalist and Foundationalist approaches to human rights, as well as the differences between Metaphysical Foundationalism and Natural Law Foundationalism. In Part III, I discuss the ethnocentricity objection to Foundationalism that gives Functionalism its appeal. I argue that Natural Law Foundationalism is a promising view because it is postured in a way that allows it to specifically confront that objection. The posture of Metaphysical Foundationalism, by contrast, only allows it to confront the objection indirectly. In Part IV, I take steps towards showing that Natural Law Foundationalism can deliver on its promise. I do so by exploring John Finnis's contention that the human goods posited by

6 John Finnis, Natural Law and Natural Rights (Oxford University Press, 2nd edn 2011). 
the view are self-evidently discoverable from the perspective of natural human practical reason. In Part V, I build on his contention to show that Natural Law Foundationalism can offer at least a plausible response to the ethnocentricity objection.

\section{FUNCTIONALISM, METAPHYSICAL FOUNDATIONALISM AND NATURAL LAW FOUNDATIONALISM}

\section{Functionalism}

I will begin by discussing Functionalism. Functionalism grounds the nature of a human right in its practical significance. A human right represents a norm the protection, recognition or violation of which gives states reasons for behaving in certain ways in the global forum of political action. The basis for identifying exactly what these reasons are is taken to be the practice of the legal-political human rights regime itself. Joseph Raz explains that the primary task of Functionalism is 'to establish the essential features which contemporary human rights practice attributes to the rights it acknowledges to be human rights.' Similarly, Charles Beitz holds that Functionalism frames our understanding of what kind of thing a human right is by identifying the roles that a human right plays within the practice of the human rights regime. By registering the practical inferences that would be drawn by competent participants in the practice from what they regard as valid claims of human rights, Beitz claims, we can generate a view of the functions of human rights that informs an account of their nature. ${ }^{8}$

John Rawls's influential account of human rights precipitated modern Functionalism. In The Law of Peoples he states, 'Human rights are a class of rights that play a special role ... they restrict the justifying reasons for war and its conduct, and they specify limits to [a] regime's internal autonomy. ${ }^{9}$ This conception of the role of human rights reflects how the post-World War II human rights regime has altered interactions between sovereign states at the global level. The regime has made it the case that states' sovereignty is limited to their conformity to the norms codified in positive human rights texts. War is no longer an admissible means of government policy; instead, it is (normally) justified only in urgent cases of intervention to protect human rights. ${ }^{10}$ Building on Rawls's view, Raz holds that human rights

$7 \quad \operatorname{Raz}(\mathrm{n} 4) 237$.

8 Beitz (n 3) 102.

9 Rawls (n 5) 79.

10 Ibid. I say that war is normally justified only in these circumstances in order to leave room for the permissibility of states engaging in just war efforts where such efforts are needed for them to defend themselves from military threats. The morality of war is a topic I will not examine here. For further discussion of the morality of war, see Tom Hurka, 'Proportionality in the Morality of War' (2005) 33(1) Philosophy and Public Affairs 34; Jeff McMahan, 'Just Causes for War' (2005) 19(3) Ethics and International Affairs 1. 
set limits to the sovereignty of states, in that their actual or anticipated violation is a (defeasible) reason for taking action against the violator in the international arena, even when-in cases not involving violation of either human rights or the commission of other offencesthe action would not be permissible, or normatively available on the grounds that it would infringe the sovereignty of the state. ${ }^{11}$

Thus, a key assertion of Functionalism since Rawls's seminal account is that, within the practice of the legal-political universal human rights regime, international human rights norms define the parameters of a state's sovereignty. A state forfeits its sovereignty if it violates those norms or fails to take positive steps to honour them within its territory. ${ }^{12}$ This violation or failure gives other political actors a reason to intervene in that state's territory to secure its citizens' human rights through diplomatic, economic or military measures, and it functions to disable the state from appealing to its sovereignty to resist such intervention. ${ }^{13}$

Functionalism does not deny that a goal of human rights norms is to protect important human interests against oppression or neglect. ${ }^{14}$ It just denies that human rights are grounded in a foundational, pre-political moral substratum that determines what those human interests are. ${ }^{15}$ This is the approach recommended by Foundationalism, which we will consider below. Instead, Functionalism grounds human rights in a construal of what it means for participants in the international human rights regime to recognise norms that protect important human interests, having particular regard to the norms' role in constraining the conduct of states.

\section{Metaphysical Foundationalism}

I will now focus on Foundationalism. Foundationalism grounds the nature of a human right in normative considerations that are conceptually prior to any positive institutions that codify or make use of human rights. It formulates the assertion that a person's human rights are to be legally protected through two serially ordered but complementary movements of thought. First, it isolates morally significant characteristics that a person has simply in virtue of her humanity, independently of any social, political or legal association to which she belongs. Second, it regards these characteristics as univer-

11 Raz (n 4) 328.

12 Rawls (n 5) 80. See also Tasioulas, 'Towards a Philosophy of Human Rights' (n 4) 19.

13 The actions for which human rights norms give reasons are, however, not limited to interventions into other states' sovereignty on a Functionalist view. Legal recognition of human rights in international documents may give states reasons to enact domestic human rights legislation, to initiate social, economic or environmental policies to secure its citizens' human rights, or to hold other states accountable for initiating such policies within their own jurisdiction. Beitz also argues that human rights norms give reasons for a state to assist another state in satisfying those norms, if the other state lacks the capacity to do so. See Beitz (n 3) 109.

14 For a Functionalist's endorsement of this precept, see ibid.

$15 \operatorname{Raz}(\mathrm{n} 4) 332$. 
sal human interests, goods or values attracting the special legal protection of a positive human rights regime. ${ }^{16}$ Hence, it posits a deep moral foundation on which legal recognition of human rights ought to be based.

James Griffin's view of human rights provides an instructive exemplar. For Griffin, what is normatively distinctive about humanity-what gives us our special moral status - is our capacity to formulate and pursue a conception of the good life. Our lives are distinguished from those of non-human animals because we are agents, 'deliberating, assessing, choosing, and acting to make what we see as a good life for ourselves. ${ }^{17}$ The universal human interest that attracts the legal protection of positive human rights regimes is thus agency or 'personhood.' ${ }^{18}$

Tasioulas rejects Griffin's Foundationalist view in favour of one that countenances a plurality of universal human interests that attract special legal protection. For Tasioulas, there is more to what makes human life go well than just agency. Insisting on agency, he claims, overlooks how some rights-violating actions can compromise several human values:

The human right not to be tortured, one might plausibly think, owes its existence to the way in which torture imperils a plurality of human interests. Victims of torture not only suffer excruciating pain, their physical and mental health is threatened, as is their capacity to form intimate relationships based on trust, all this in addition to the way that torture attacks their autonomy or agency. ${ }^{19}$

Tasioulas holds that other universal human interests, in addition to agency, that provide a moral foundation for human rights include health and accomplishment. ${ }^{20}$

The shared feature of these Foundationalist accounts to which I want to draw attention is that they have what might be called a distinctive theoretical posture. They approach the issue of which universal human interests attract positive legal protection using a distinctive third-personal or metaphysical methodology. The methodology consists in an observer's conceptual analysis of the idea of humanity, of what makes human life go well, or of what makes human nature especially valuable, worthwhile or of special normative status. The resulting normative characteristic or characteristics, putatively possessed by a person simply in virtue of her humanity, are therefore discernible from a

16 For discussion and criticism of this second aspect of the Foundationalist strategy, see ibid at 323-4.

17 Griffin (n 3) 32.

18 Ibid, 33. Griffin holds that the value of agency divides into three components: autonomy, which denotes our interest in not being controlled by something or someone other than ourselves; 'minimum provision', which denotes our interest in having the information, education, resources or capabilities that make our choices real; and liberty, which denotes our interest in freedom from being constrained from pursuing what we regard as a worthwhile life. See also ibid, 149-87.

19 Tasioulas, 'Towards a Philosophy of Human Rights' (n 4) 13.

$20 \mathrm{Ibid}, 14$. Tasioulas regards it as an advantage of his view that it avoids potentially excluding from the protection of human rights human beings who are not agents, such as newborns, comatose individuals, or those suffering from advanced dementia. 
third-personal, metaphysical perspective. They then furnish an assertion that they ought to be protected by the legal-political universal human rights regime. Having in view this conception of the posture of the theories of human rights exemplified by Griffin and Tasioulas, I shall call them Metaphysical Foundationalist theories.

\section{Natural Law Foundationalism}

I will now consider Natural Law Foundationalism. This view interprets the idea that human rights are specially connected to the notion of humanity by holding that the normative considerations which ground human rights are universal human goods discoverable by the natural use of human practical reason. The view has not been developed as extensively as Metaphysical Functionalism. Consequently, Functionalist critics of Foundationalism do not regard it as their primary interlocutor. Beitz, for instance, calibrates his attacks on Foundationalism by setting aside Natural Law Foundationalism, principally because '[Metaphysical Foundationalism] has been more influential in modern political thought. ${ }^{21}$

Natural Law Foundationalism takes inspiration from the natural law tradition. John Finnis describes natural law theory as holding that 'there is a set of basic practical principles which indicate the basic forms of human flourishing to be pursued and realised, and which are in one way or another used by everyone who considers what to do..2 On natural law theory, the pursuit of universal human goods is a fundamental requirement of natural human practical reason. Thus, to discover what the universal goods are, it is necessary to determine what the requirements of practical reason are. We can have selfevident knowledge of the universal goods because the requirements of practical reason are self-evidently knowable through the natural use of human practical reason itself. ${ }^{23}$

In working with these assertions about natural law theory, I do not aim to defend or rely on any particular catalogue of universal human goods that serve as commitments of practical reason. Different natural law theorists countenance different catalogues. Finnis's catalogue includes life, knowledge, play, aesthetic experience, friendship, practical reasonableness, and religion. ${ }^{24}$ The natural law theorist Mark Murphy's catalogue includes life, knowledge, aesthetic experience, excellence in play and work, excellence in agency, inner peace, friendship and community, religion, and happiness. ${ }^{25}$ For my purposes, I draw upon the structure of natural law theory to make the following three interrelated claims about Natural Law Foundationalism:

Beitz (n 3) 52. It is telling that Beitz cites the work of John Finnis when describing the sort of Foundationalist view that he ignores (at 52).

22 Finnis (n 6) 23.

23 Ibid, 85-86.

24 Ibid, 86-90.

25 Mark Murphy, Natural Law and Practical Rationality (Cambridge University Press, 2001) 101-35. 
- It is a type of Foundationalism. It grounds the nature of human rights by linking it with the notion of humanity and by identifying normative considerations in the context of a pre-political substratum of moral thought to which positive institutions ought to conform. ${ }^{26}$

- The aforementioned link is forged by the view that there are universal human goods the pursuit of which is a requirement of natural human practical reason. These goods serve as the foundational, pre-political normative considerations that attract the special legal protection of the positive human rights regime.

- Knowledge of the universal human goods is self-evident. From the perspective of natural human practical reason itself, it is self-evident that the universal human goods are fundamental commitments of natural human practical reason.

I want to draw attention here to the distinctive theoretical posture of Natural Law Foundationalism. Notice that its methodology for identifying universal human goods is first-personal, practical and epistemological. It holds that universal human goods are such as to attract protection because of their special epistemological status. Their importance derives from the way in which they are discovered; pursuit of the universal goods is a requirement of natural human practical reason, and this is knowable self-evidently, simply by reflecting on what it is like to be a human practical agent from the first-personal point of view of human practical reason itself. The view appeals to the phenomenology of agency and discerns the requirements of human practical reason from the perspective of the participant in human practical reason, ie from her judgments, valuations and experiences, and from the way in which normativity is disclosed to her.

In this respect, the theoretical posture of Natural Law Foundationalism differs from that of Metaphysical Foundationalism. For Metaphysical Foundationalism, recall, the universal human interests to which the legal-political human rights regime is answerable are identified through third-personal conceptual analysis of the idea of humanity. This analysis leads to the conclusion that the universal human interests are what make human nature or human life normatively distinctive, as distinguished from the nature or lives of non-human animals. They therefore owe their importance to their special metaphysical status.

It should be noted that the universal human goods on Finnis's account are not fully articulable in the context of a pre-political substratum of moral thought because they necessitate a form of human community, which ultimately forms the basis of Finnis's views on politics and jurisprudence: Finnis (n 5) 125. See also Beitz (n 2) 50-52. An analysis of the connection between the natural law theory of practical rationality and the natural law theory of politics and jurisprudence is beyond the scope of this essay, but that is not to say that the connection is uninteresting and unimportant. For discussion, see Murphy (n 25) 3. 


\section{THE ETHNOCENTRICITY PROBLEM AND THE PROMISE OF NATURAL LAW FOUNDATIONALISM}

\section{The Ethnocentricity Problem}

Having defined the landscape of the clash between Functionalism and Foundationalism, and having located Natural Law Foundationalism within this landscape, I will now consider the main objection to Foundationalism that gives Functionalism its appeal. I will call it the Ethnocentricity Problem. The Ethnocentricity Problem poses a question to the Foundationalist: How can we know for certain that the pre-political normative considerations to which the positive human rights regime ought to conform are universally applicable across cultures?

Human rights purport to protect all people from abuses of state power, even when those people disagree radically over moral, political, religious, cultural or philosophical worldviews. ${ }^{27}$ A Foundationalist theory of the nature of human rights therefore fails if the moral foundations for human rights that it countenances are not applicable to all people and across a wide variety of cultures. That is, it is defective to the extent that those foundations are ethnocentric. The foundations are ethnocentric if they are applicable within only a particular moral, political, religious or philosophical culture, or are unable to translate into an argument for their universality that is convincing for members of a different culture.

It is thus a crucial desideratum for any Foundationalist theory that it responds to the Ethnocentricity Problem. Since Foundationalism holds that a person has a human right simply in virtue of humanity, it is susceptible to the danger that its operative notion of humanity is only acceptable within local cultures, rather than universally across cultures.

The appeal of Functionalism is that it deftly sidesteps the Ethnocentricity Problem. In grounding human rights in the roles that they play within the practice of the positive human rights regime, Functionalism avoids committing to any pre-political normative considerations or views on the notions of humanity and human nature. It therefore avoids inviting the objection that these considerations or views may be ethnocentric. Rawls states that human rights

do not depend on any particular comprehensive religious doctrine or philosophical doctrine of human nature. The Law of Peoples does not say, for example, that human beings are moral persons and have equal worth in the eyes of God; or that they have certain moral and intellectual powers that entitle them to these rights. To argue in these ways would involve religious or philosophical doctrines that many decent hierarchical peoples might reject as liberal or democratic, or as in some way distinctive of Western political tradition and prejudicial to other cultures. $^{28}$ 
Similarly, Beitz writes that, for Functionalism, '[ $\mathrm{t}$ ] here is no assumption of a prior or independent layer of fundamental rights whose nature and content can be discovered independently of a consideration of the place of human rights in the international realm and its normative discourse..29

The Ethnocentricity Problem poses a particularly acute problem for Metaphysical Foundationalism. On this view, recall, the pre-political normative considerations that ground human rights are universal human interests. This conclusion is arrived at through conceptual analysis of the notion of humanity, or of what makes human life go well. But this analysis, at least for thinkers such as Griffin and Tasioulas, occurs in the context of a liberal-democratic moral tradition. It therefore invites the worry that the concept of humanity under analysis has a particular cultural connotation specific to the liberal-democratic tradition. ${ }^{30}$ Thus, doubt arises as to whether the analysis yields a view of human interests that is truly universal.

Indeed, some cultures may not value such interests as agency, autonomy, liberty or accomplishment as highly as the liberal-democratic culture. They also may not share the metaphysical presuppositions of Christianity, with its emphasis on freedom of the will, out of which the liberal-democratic culture grew. Saba Mahmood, for example, describes how individuals taking part in the women's Islamic social movement in Egypt place value on a life of passivity and subservience, rather than on the activity constitutive of the liberal-democratic conceptions of autonomy and accomplishment. ${ }^{31}$

\section{The Promise of Natural Law Foundationalism}

How might the Metaphysical Foundationalist respond to the Ethnocentricity Problem? The nature of the problem mandates that she cannot appeal to the authority of the cultural context in which her conception of universal human interests is rooted. She cannot, for example, argue that everyone can know that agency is a universal human interest because it is known to be so within the liberal-democratic tradition. This approach is unconvincing for members of cultures other than those to whose authority it appeals. It gives no argument that could be accepted by members of other cultures for why the moral beliefs within liberal-democratic cultures should determine what counts as a universal human interest.

But notice that if it does give such an argument, it no longer amounts to an appeal to authority. Rather, it becomes a substantive first-order normative argument about the rational credentials of liberal-democratic moral beliefs concerning the universality of human interests. Hence, the Metaphysical Foundationalist must ultimately offer this sort

29 Beitz (n 3) 102.

30 Even Griffin recognises that the tradition of human rights thinking in which he writes has a history rooted in Catholic theology and Enlightenment ideals of personhood: Griffin (n 3) 9-14, 30-31.

31 Saba Mahmood, 'Feminist Theory, Embodiment and the Docile Agent: Some Reflections on the Egyptian Islamic Revival' (2001) 16(2) Cultural Anthropology 202, 212-23. 
of substantive defence of the moral beliefs about universal human interests formulated within the liberal-democratic culture. This is the only tractable way to convince members of other cultures that those beliefs ought to be accepted, and thereby address the Ethnocentricity Problem.

We find the representative Metaphysical Foundationalists in fact taking just this route. For Tasioulas, 'whether or not a candidate norm is really a human right is to be determined by ordinary ... moral reasoning. ${ }^{32}$ Griffin argues that, in order to bring about 'unforced agreement on human rights', we must 'put the case for human rights as best we can construct it from resources of the Western tradition, and hope that nonWesterners will look into the case and be attracted by what they find. ${ }^{33}$

It is helpful to clarify this important point using an example. Consider Jane, a representative Metaphysical Foundationalist in the liberal-democratic tradition, and Elizabeth, a member of a non-liberal culture. Jane holds moral beliefs about universal human interests. She aims to convince Elizabeth to accept them. How might she do this?

To appeal to the authority of the liberal-democratic culture is, as we have seen, illicit. So Jane must engage Elizabeth's practical reason directly through ordinary moral reasoning. She must attempt to elicit Elizabeth's assent by relying only on the rational force of the better moral argument ${ }^{34}$ that the universality of the human interests to which she is committed really is knowable as such by all people everywhere. She might try to have Elizabeth accept abstract first principles from the perspective of practical reason, and show her that a commitment to the human interests that she defends follows from them. Alternatively, she might construct thought experiments to show Elizabeth that her considered practical judgments about them disclose that the human interests in question are knowable as universal. But Jane cannot rationally allow Elizabeth to reject her moral beliefs simply on the grounds that they are formulated within the liberal-democratic context. Elizabeth would thereby make an illicit appeal to authority in the opposite direction.

The lesson is that Jane's goal must be to convince Elizabeth that acceptance of her moral beliefs is mandated from the perspective of practical deliberation itself. It must be to show that the universality of the human interests that she defends is discoverable by attending closely to the phenomenology of agency, and the way in which normativity is disclosed from a first-personal point of view. Jane must convince Elizabeth about the rational credentials of her moral beliefs by appealing, not to the authority of liberaldemocracy, but to the authority of the requirements of natural human practical reason. In other words, her beliefs' credentials must derive from their special epistemological status as requirements of practical reason.

32 Tasioulas, 'Triggers' (n 4) 938.

33 Griffin (n 3) 137.

34 I borrow this phraseology from Jürgen Habermas. See his Between Naturalism and Religion: Philosophical Essays (Polity Press, 2008) 16. 
Jane can only achieve her goal by adopting the perspective of practical deliberation herself. She must cooperatively aid the disclosure to Elizabeth of the requirements of practical reason from the first-personal perspective, using 'ordinary moral reasoning' to bring about Elizabeth's 'unforced agreement'. Of course, this does not entail that Jane may not eventually decide that her beliefs about universal human interests were incorrect all along. Indeed, Elizabeth may show that Jane has incorrectly grasped the requirements of practical reason, or that she has not attended correctly to the disclosure of normativity from a phenomenological point of view. But if this occurs, it must be the authority of practical deliberation that holds sway over Jane's decision, and nothing else.

This, then, must be the methodology by which Metaphysical Foundationalism addresses the Ethnocentricity Problem. Whether or not it succeeds is a question that I will not pursue. ${ }^{35}$ What is important for my purposes is that the methodology has a firstpersonal, practical or epistemological posture. To address the Ethnocentricity Problem, Metaphysical Foundationalists must shift gears from the third-personal posture in which they identify, through conceptual analysis, the human interests that they purport to be universal, to a first-personal, practical and epistemological posture. Put otherwise, to ratify the results of their conceptual analysis, Metaphysical Foundationalists must overcome skeptical doubt about their beliefs concerning the universality of basic human interests by appealing to the requirements of practical reason from the perspective of practical reason itself. That this must be the case is unsurprising, given that the Ethnocentricity Problem is framed in epistemological terms; it asks Foundationalists how we can know of the cross-cultural applicability of purportedly universal human interests.

Now, the methodology by which Metaphysical Foundationalism must address the Ethnocentricity Problem is precisely the methodology by which Natural Law Foundationalism begins its investigation of universal human goods. As I argued earlier, the posture of Natural Law Foundationalism is first-personal, practical and epistemological; it takes the universal human goods to be fundamental requirements of natural human practical reason, self-evidently discoverable through the natural operation of practical reason itself. Natural Law Foundationalism is therefore inherently well suited to addressing the Ethnocentricity Problem. Its posture allows it to address the Ethnocentricity Problem less circuitously than Metaphysical Foundationalism. It proposes that knowledge of the universality of certain human goods is tightly connected with knowledge of the requirements of practical reason. It does so at the start of its analysis, rather than first identifying human interests, and then having to justify the moral beliefs in the universality of those interests. Because Natural Law Foundationalism's identification of universal human goods relies on those goods' epistemological credentials from a first-personal, practical perspective, it is better suited to confronting the Ethnocentricity Problem (which raises skeptical doubt about those credentials) than is Metaphysical Founda- 
tionalism, which identifies universal human interests by relying on their metaphysical credentials, as they are ascertained from a third-personal, conceptual point of view.

I therefore submit that Natural Law Foundationalism is a promising view that deserves closer attention and more extensive development. Its theoretical posture is such as to directly confront the main objection to Foundationalism that makes Functionalism an attractive view to many philosophers. By contrast, the theoretical posture of Metaphysical Foundationalism only allows it to address the Ethnocentricity Problem in an indirect, roundabout fashion. In the remainder of this essay, I will take preliminary steps towards showing how Natural Law Foundationalism can deliver on its promise.

\section{PRACTICAL REASON AND THE SELF-EVIDENCE OF UNIVERSAL HUMAN GOODS}

\section{Finnis's Account}

My argument so far has been largely meta-theoretical. I have spoken broadly of the posture and the promise of Natural Law Foundationalism. The argument must now be magnified. To show that Natural Law Foundationalism can make good on its promise, I will examine its main tenets more closely. These tenets, recall, are that human rights are grounded in universal human goods that attract the protection of positive legal institutions. The pursuit of these goods is a fundamental requirement of natural human practical reason. The goods are self-evidently knowable as universal because the requirements of practical reason are self-evidently knowable as such. In this Part, I intend to exhibit the philosophical plausibility of these assertions.

Finnis defends a natural law account of how we come to self-evidently know human goods and the requirements of practical reason. His account has two components. First, he claims that human beings experience, from a practical perspective, 'inclination [s]' to engage in certain activities, or tendencies or dispositions towards doing certain kinds of actions. ${ }^{36}$ It is a natural feature of human practical reason to have such phenomenological experiences; having them is one way in which normativity is disclosed to us first-personally. Finnis's example is the inclination to curiosity or the tendency towards inquiry. Upon reflection, however, we find that our tendency to inquire into the truth of a matter is not restricted by the particular questions which initially precipitated our curiosity: 'One finds oneself reflecting that ignorance and muddle are to be avoided, simply as such and not merely in relation to a closed list of questions that one has raised. ${ }^{37}$ From this we notice that knowledge is a good to be pursued, not merely for its utility in answering the initial questions, but intrinsically and in general. Thus, upon reflection 
we move from our initial inclinations to grasp of value-in Finnis's example, the value of knowledge.

Second, Finnis holds that it is indubitable that the objects which our experiences of practical inclinations incite us to grasp really are universal human goods. The goodness of those objects is, as Finnis says, 'self-evident, obvious. ${ }^{38}$ Knowledge of their goodness requires no philosophical demonstration. In particular, their goodness cannot be derived from the fact that we experience inclinations to do certain acts, since 'no value can be deduced from a fact. ${ }^{39}$ Thus, knowledge of human goods is self-evident because it is (a) underived knowledge and (b) not philosophically demonstrable knowledge.

Finnis's account clearly leaves us with some puzzling questions: What exactly does it mean to say that something is a requirement of practical reason? What does it mean to say that it is self-evidently knowable because knowledge of it is underived and undemonstrable? How does the self-evidence of these requirements connect to inclination, grasp of value, and knowledge of human goods? In what follows I will consider and reject one initial approach to answering these questions, and then submit my own approach.

\section{Intuitionism}

On what I will call an intuitionist approach ${ }^{40}$ to interpreting Finnis's account, human beings have a special faculty that imparts direct cognitive access to value, analogous to how vision gives us cognitive access to physical objects. The proposed faculty first operates through rudimentary features of our practical reason, namely, inclinations or tendencies towards certain acts, such as curiosity. By manifesting in these requirements of practical reason, it directs our attention towards values, such as knowledge. We then come to self-evidently know of human goods because the proposed faculty allows us to cognitively 'latch on' to them, and thereby grasp them.

This approach might seem attractive at first blush. It offers a simple explanation of how we self-evidently know the human goods from a practical, first-personal perspective, and of how normativity is disclosed to us phenomenologically. It also explains how this knowledge is underived and undemonstrable by interpreting Finnis as holding that we move from inclination to grasp of value through an immediate, 'flash of insight' process. But the approach fails once we see that the special faculty that it posits can be construed in two equally problematic ways.

On the one hand, the faculty might be construed as describable in purely material terms, as physical organs of the human body might be. That is, its operation may be purely describable in terms of organic tissue, the firing of nerve-endings, etc. If so, its

38 Ibid, 65.

39 Ibid, 66.

40 It could be possible to interpret Haight and Joseph's work along the lines of the intuitionist approach that I canvass here. See Jonathan Haight and Craig Joseph, 'Intuitive Ethics: How Innately Prepared Intuitions Generate Culturally Variable Virtues' (2004) 133 Daedalus 5. 
malfunction —its failure to 'latch on' to value-should be describable simply in terms of some mechanical defect in its material operations.

This is not, however, how Finnis describes a mature person's inability to grasp human goods. He says that to deny a human good is 'as straightforwardly unreasonable as anything can be ${ }^{41}$ For Finnis, failure to grasp a human good is attributable to some normative failure of reasonableness, not to some mechanical failing in our biological hardware. Finnis is also clear that the question of how we move from inclination to grasp of value is not answerable by pointing to our organic constitution or to the biological preconditions of that grasp. ${ }^{42}$ Thus, this first construal of the intuitionistic approach does not offer an accurate interpretation of Finnis's account.

To avoid this difficulty, the faculty for cognitively accessing value posited by the intuitionistic approach might be construed non-materially. It may be regarded as something embedded in the human mind that allows us to latch on to value, yet not something, say, embedded in the human brain. It may be like a faculty, or the same faculty, that allows us to grasp non-tangible, abstract objects, such as numbers, propositions or aesthetic qualities. Of course, we should be wary when positing such a faculty. Its non-material nature renders it unable to be verified by scientific investigation, leaving us with unstable grounds for ontologically committing to it. However, it could be that the faculty has a psychological existence, similar to such familiar notions as personality-types or an innate mental structure that allows us to acquire language. If its existence is similar to these accepted aspects of the human mind, it may not be totally impervious to empirical verification.

But this line of thought leads to further interpretive difficulties. Finnis states that the capacity to know of the human goods 'is not somehow innate, inscribed on the mind at birth. ${ }^{43}$ It must therefore differ from such mental faculties as the capacity to acquire language. Finnis also holds that it is not relevant to ask a psychologist's opinion about whether something is a human good to discover whether it is so. On his account, knowledge of human goods has no 'sub-rational cause. ${ }^{44}$ It is therefore dissimilar to something like a personality-type.

Hence, neither the materialistic nor the non-materialistic construal of the faculty posited by the intuitionistic approach to interpreting Finnis's account actually harmonises with his account. We should therefore reject it as an implausible interpretive approach, and search for an approach that is harmonious with Finnis's account.

\footnotetext{
41 Finnis (n 6) 69 (emphasis added).

42 Ibid, 65.

43 Ibid.

44 Ibid.
} 


\section{The Human Goods as Intelligibility-Conditions}

When discussing the human good of knowledge, Finnis states that, in explaining what one is up to when one is inclined towards investigating a subject-matter which has aroused one's curiosity, 'one finds oneself able and ready to refer to finding out, knowledge, truth as sufficient explanations of the point of one's activity, project or commitment. ${ }^{45} \mathrm{He}$ also asks, 'Is it not the case that knowledge really is a good ... and that the principle which expresses its value formulates a real (intelligent) reason for action?' ${ }^{46}$ These remarks suggest that, on natural law theory, the human goods represent reasons for action from the first-personal, phenomenological perspective of practical reason. They explain why we do what we do. If I do not recognise that the good of knowledge provides a reason for me to inquire into the truth of a matter in some situation, I would find my act of inquiry inexplicable and pointless, lacking a basis in rationality or intelligibility. As Finnis says, 'In trying to make sense of someone's commitments, projects, and actions over a period, we may say that he acted "on the basis that" knowledge is a good worthy of a life-shaping devotion. ${ }^{\text {, }}$

Building on these remarks, I propose the following as an approach to understanding Finnis's account of how we come to self-evidently know the human goods and the requirements of practical reason. ${ }^{48}$ The human goods provide basic reasons for action from a first-personal, practical point of view. Their pursuit is a requirement of natural human practical reason because they must be postulated, from the practical perspective, as reasons for us to engage in the activities we have tendencies, inclinations or dispositions to engage in. Postulating them as reasons for action confers intelligibility on our inclinations. The human goods are conditions of the intelligibility of our inclinations. They enable our tendencies to do certain acts to make sense to us phenomenologically. For example, my inclination to seek medical assistance when I am grievously injured is rendered intelligible because I take the goodness of my life as a reason for seeking medical assistance. On the approach I defend, to move from inclination to grasp of value is to reflect on and recognise the need to postulate the human goods as reasons for action that confer intelligibility on our inclinations.

The requirements of practical reason, and hence the human goods, are knowable self-evidently because to deny them entangles us in a form of practical contradiction. ${ }^{49}$ Denying that the human goods are reasons for action deprives us of a basis for claiming that the actions towards which we are inclined are intelligible. It deprives us of the

Ibid, 61 (emphasis in original).

Ibid, 64 .

47 Ibid.

48 I have benefited greatly from Mark Murphy's writings on natural law theory in thinking through this proposal. See especially Murphy (n 25) 1-3, 6-13.

49 Finnis similarly argues that skepticism about the goods of knowledge is impossible because to deny that knowledge involves one in a performative contradiction. See Finnis (n 6) 73-75. 
grounds for understanding how and whether our tendencies can make sense to us from a first-personal point of view. As Finnis argues, the requirements of practical reason are self-evident in much the same way as the requirements of theoretical rationality, such as the requirement that self-contradictory theses should be abandoned, and that simple, predictively successful and explanatorily powerful theses should be preferred. Denying the requirements of theoretical rationality disables us from making sense of our tendency to assent to empirical theses conforming to them. It deprives us of a basis for claiming that such assent is intelligible. ${ }^{50}$

Furthermore, on the approach I defend, a person's failure to grasp the human goods is a normative failing or a failure of reasonableness. It consists in a failure to reflect on and recognise that the human goods must be postulated as reasons for action that confer intelligibility on our inclinations. It disables us from understanding how our tendencies to do certain acts can make practical sense to us. This approach therefore succeeds where the intuitionist approach falls short. The intuitionist approach (at least on a materialist construal of the special faculty that it posits for cognitively accessing value), recall, can regard a failure to grasp the human goods only as a non-normative, mechanical failure.

My approach can also explain how self-evident knowledge of the human goods and of the requirements of practical reason is underived knowledge. It is underived because it is arrived at by postulating that the human goods are intelligibility-conferring reasons for the actions towards which we are inclined. It is not arrived at by deriving the human goods from the fact that we have a disposition towards certain acts. This can be seen once it is recognised that a postulate is distinct from a derivation. A postulate is a self-evident premise from which a conclusion may be drawn. By contrast, a derived proposition is a conclusion drawn from a set of premises. To derive a proposition ' $\mathrm{Y}$ ' from another proposition ' $\mathrm{X}$ ' requires asserting the proposition 'If $\mathrm{X}$ then $\mathrm{Y}$ '. To postulate ' $\mathrm{Y}$ ' as an explanation for ' $\mathrm{X}$ ' requires asserting 'If $\mathrm{Y}$ then $\mathrm{X}$. I do not claim here that if we are inclined towards a certain act then to do the act is to pursue a human good. Rather, I claim that if our inclination to do a certain act is explicable as intelligible, then pursuit of a human good is a reason to do that act that confers intelligibility on it. ${ }^{51}$

Since we arrive at knowledge of the human goods and the requirements of practical reason by postulating that the human goods are intelligibility-conferring reasons for actions towards which we are inclined, it is also undemonstrated knowledge. To postulate a proposition is not to provide a philosophical argument for it. Rather, it is to assert it as a premise or starting point from which to provide philosophical arguments for other propositions. That does not mean that we lack rational grounds for making postulates. Although they are not argued for, they are presupposed in order to explain or render intelligible certain phenomena, such as the inclinations we experience or our tendency to assent to certain empirical theses. Such presuppositions can be more or less rational according to their explanatory or intelligibility-conferring capabilities.

51 For discussion, see ibid, 63-64. 
In summary, on my approach, the human goods and the requirements of practical reason are self-evident because they have the status of pre-philosophical postulates. The need to postulate them is graspable by reflecting on the reasons that make our practical tendencies intelligible to us from a first-personal perspective. A catalogue of human goods to pre-philosophically postulate can be adjudged as more or less rational according to the effectiveness with which it confers intelligibility on our tendencies. The rationality of the catalogue also depends on the propriety of the resources that it offers to furnish normative philosophical arguments that the human goods it includes ought to attract the protection of the positive legal-political human rights regime.

\section{THE ETHNOCENTRICITY PROBLEM REVISITED}

\section{Perry's Objection}

To review, Natural Law Foundationalism is a promising view because its theoretical posture is such as to allow it to confront the Ethnocentricity Problem more straightforwardly than Metaphysical Foundationalism. Unlike Metaphysical Foundationalism, it exhibits a practical, first-personal theoretical posture from the start of its analysis. It holds that the human goods which attract the protection of positive institutions owe their importance to their epistemological status as self-evident requirements of natural human practical reason. It therefore promises to be able to directly assuage the skeptical doubts about the universality of those goods raised by the Ethnocentricity Problem. In addition, Natural Law Foundationalism can deliver on its promise. There is a plausible argument available for its central contention that the human goods are requirements of practical reason. On this argument, the human goods are conditions of the intelligibility of our practical inclinations. We can self-evidently know, from a practical, first-personal perspective, that there are important human goods linked to the notion of humanity itself. Such knowledge arises from attending to the disclosure of normativity from a phenomenological view of what it is like to be a human being with natural human practical reason. This phenomenological view discloses that the human goods are reasons for action that render our practical dispositions intelligible.

Natural Law Foundationalism must now confront the Ethnocentricity Problem. How can we know that the human goods are universally applicable across cultures, rather than just for those of us within the liberal-democratic context? The possibility of self-evident knowledge of the universality of human goods, on Finnis's account, has recently been challenged by Michael Perry. ${ }^{52}$ Perry's objection is that even if I (or members of my culture) self-evidently know, from my (our) first-personal perspective, that a human good must be posited as an intelligibility-conferring reason for my inclinations,

52 Michael J Perry, Towards a Theory of Human Rights: Religion, Law, Courts (Cambridge University Press, 2007). 
it does not follow that the same good must be postulated as an intelligibility-conferring reason for the inclinations of members of cultures other than mine (ours), from their own first-personal perspective. If that is true, then I cannot self-evidently know of the universality of that good. I cannot claim to know that members of other cultures act contrary to the requirements of practical reason by denying or failing to grasp a human good just because it would be contrary to those requirements for me to do so. Although my denial renders the actions towards which I am inclined to be unintelligible, it does not follow that the same is true for others. ${ }^{53}$

Indeed, human rights may be grounded in human goods that impart intelligibilityconferring reasons for our inclinations from the perspective of natural human practical reason. And these goods may derive their importance from their status as self-evidently knowable requirements of practical reason. But if members of the liberal-democratic culture cannot know that members of other cultures experience the same inclinations as they do, they cannot self-evidently know of the cross-cultural applicability of the human goods that confer intelligibility on our inclinations. The postulation of those goods would not be required to render intelligible the practical dispositions that all persons have simply in virtue of possessing natural human practical reason if there are no such dispositions.

\section{How Natural Law Foundationalism Responds to the Ethnocentricity Problem}

Natural Law Foundationalism's response to these problem posed by Perry builds on Finnis's writings. Finnis claims that the way in which natural law theory identifies the human goods (and, hence, the requirements of practical reason) is not limited to the horizon our own first-personal perspective, although this is its starting point and ultimate normative resource. Rather, we can partly base our postulations of the intelligibility-conferring reasons for our inclinations on third-personal observations of the commitments, activities and experiences of members of other cultures from their first-personal perspective. Finnis states that the 'plasticity of human inclinations, which correlates with the generality or universality of the corresponding values understood by one's practical intelligence, is important for an accurate grasp ... of the human virtues and vices. ${ }^{54}$ Our third-personally acquired information of other cultural conventions, however, does not furnish a derivation of values from facts. Instead, it corroborates our own postulations of human goods from our own practical perspective. ${ }^{55}$

For natural law theory, we can ultimately be sure about the universality of human goods by exposing ourselves to the experiences of other cultures. By observing the variety of different cultural activities, we can discover third-personally that members of 
other cultures experience first-personally the same inclinations to engage in certain acts that those of us in the liberal-democratic context experience. This is true even though the inclinations manifest themselves diversely.

Since we can self-evidently know of human goods because they impart intelligibility-conferring reasons for our inclinations, and since we can observe that all persons experience inclinations that are similar to ours, we can self-evidently know the human goods as postulates that confer intelligibility on all persons' inclinations. As Finnis writes, our observations 'open to us a revelation or reminder of the range of opportunities open to us in shaping our own life through the free and selective pursuit of the basic values. ${ }^{56}$ Hence, Natural Law Foundationalism's response to the Ethnocentricity Problem is this: Knowledge of the universality of the human goods that impart reasons for action is self-evident because pursuit of the human goods renders intelligible the actions towards which all persons in all cultures are inclined to engage in.

It might be said, however, that this response presupposes that all persons in all cultures do phenomenologically experience the same practical dispositions. But is it true that normativity is disclosed first-personally in the same way for all persons, simply because of what it is like to be a human being with natural human practical reason? Finnis, for one, answers this question in the affirmative. He holds that, in one way or another, all people cross-culturally experience dispositions towards preserving human life, educating other members of their society, reciprocally cooperating with others, engaging in recreational activities, and honouring supernatural power. ${ }^{57}$ In order to render these dispositions intelligible, we must postulate that all persons regard certain human goods, such as life, knowledge, friendship, play and religion, as imparting reasons for action. Moreover, in order for persons in other cultures to make sense of their own inclinations from their own practical point of view, they must make the same postulate.

Finnis is not alone in making this argument. Martha Nussbaum contends we can third-personally observe that all people cross-culturally have what she calls 'grounding experiences' from a first-personal point of view. ${ }^{58}$ Grounding experiences are experiences of spheres of human life that are universally salient to all persons. They are disclosed phenomenologically to natural human practical reason. While they are common to all cultures, different cultures may respond to them differently. Nussbaum states that 'everyone makes some choices and acts somehow or other in these spheres. ${ }^{59}$ On her view, everyone has attitudes, responses and behavioural dispositions towards some universally salient features of human practical life, but their interpretation of these features differs from culture to culture. For example, all persons experience some disposition to react to

Ibid, 84 .

57 Ibid, 83-84.

58 Martha Nussbaum, 'Non-Relative Virtues: An Aristotelian Approach' in Martha Nussbaum and Amartya Sen (eds), The Quality of Life (Oxford University Press, 1993) 245, 247.

59 Ibid, 247. 
mortality, pleasure and pain, and affiliation, but individuals' dispositional reactions can be manifested in variegated ways. ${ }^{60}$

Arguments such as these help to reinforce the initially controversial presupposition made by Natural Law Foundationalism's response to the Ethnocentricity Problem. We can self-evidently know that the human goods and the requirements of practical reason are universally applicable across cultures because they must be postulated as intelligibility-conferring reasons for action for the inclinations that all people experience from a first-personal perspective, simply in virtue of possessing human practical reason. Our own grasp of the need to make this postulation to render our own inclinations intelligible for us (or for people within our own culture) is self-evident. But it is substantiated by third-personal observation of the need for members of other cultures to postulate them to render their inclinations intelligible for them.

I will use another example to illustrate this response to the Ethnocentricity Problem. Recall Jane the Foundationalist and Elizabeth, a member of a non-liberal culture. Suppose that Jane is a Natural Law Foundationalist. She holds that the nature of human rights is grounded in human goods, identifiable within a pre-political substratum of moral thought, that attract the protection of the legal-political human rights regime. Knowledge of these goods is self-evident because they are postulated as reasons for action that confer intelligibility on our practical dispositions. They are therefore requirements of natural human practical reason, discoverable from the first-personal, phenomenological perspective of practical reason itself. Jane aims to convince Elizabeth of the universality of her beliefs about these human goods. How might she do so?

Jane cannot appeal to the authority of the liberal-democratic culture in which her moral beliefs were formulated. If human goods owed their importance to their status as components of liberal-democratic morality, they would not be universally applicable to all cultures. Jane must therefore engage Elizabeth's practical reason directly through substantive moral argument.

Jane is well suited to engaging Elizabeth in this way. Her moral beliefs about human goods, namely that they are self-evidently graspable by postulating the human goods as intelligibility-conferring reasons for doing the acts to which we are inclined, are formulated within the perspective of natural human practical reason itself. In this sense, the goods owe their importance to their epistemological status as requirements of practical reason. Thus, to engage Elizabeth's practical reason Jane need not exit the theoretical posture within which she first identified the human goods and shift to a practical theoretical posture. On her view, the need to postulate the human goods as reasons for action is mandated by the first-personal, phenomenological disclosure of normativity to natural human practical reason. She can therefore engage Elizabeth's practical reason and her first-personal, phenomenological perspective directly and non-circuitously. 
Now, Elizabeth might accept that, from Jane's first-personal perspective, the human goods are important because they are self-evidently knowable requirements of practical reason for Jane. She might accept the necessity of postulating the human goods as intelligibility-conferring reasons for action for Jane's inclinations. But how, Elizabeth may ask, can we know self-evidently that the human goods are universal? How can Jane know that everyone must postulate them as intelligibility-conferring reasons for action for their inclinations? How can Jane convince me that they are self-evidently knowable requirements of practical reason for me?

On Jane's view, the response to these queries is that her beliefs about the universal applicability of the human goods can be corroborated by observing third-personally the inclinations of members of many different cultures. This observation would reveal that the first-personal practical experiences of all people everywhere are similar to hers. All people everywhere have inclinations to engage in similar activities. This is so even if the ways in which these activities are engaged in are diverse or these practical inclinations are manifested in variable ways. It is typical of natural human practical reason to have these inclinations. Thus, the human goods must be postulated as intelligibility-conferring reasons for the activities towards which all people everywhere are inclined. That they must be so postulated is what makes them self-evidently knowable from the perspective of practical reason itself, for all people everywhere.

Jane can therefore extend her beliefs about the human goods beyond the horizon of her own practical perspective, and thereby have knowledge of their universality. She can justify the credentials of her beliefs to Elizabeth by pointing out that Elizabeth's own first-personal inclinations are similar to hers, even if they are manifested differently, or if Elizabeth engages in the activities towards which they are each inclined differently. She can convince Elizabeth that pursuit of human goods is also a requirement of Elizabeth's practical reason by showing her that normativity is phenomenologically disclosed to each of them in the same way. She can show Elizabeth that the human goods impart reasons for action to both of them, and allow them each to understand how their inclinations make practical sense to them from a first-personal perspective. In doing so, Jane appeals to no authority but that of natural human practical reason.

\section{CONCLUSION}

In this essay, my goal has been to construct a case for Natural Law Foundationalism as a theory of the nature of universal human rights. Generally stated, the case for this theory is that its first-personal, practical theoretical posture allows it to directly confront the main objection to all Foundationalist views that gives Functionalism its appeal, the Ethnocentricity Problem. It is therefore a promising view that merits more extensive development. Furthermore, Natural Law Foundationalism can deliver on its promise 
because its central tenets have sufficient philosophical plausibility. I have defended an interpretation of its contention, originally put forward by John Finnis, that the human goods it posits which attract the protection of the legal-political human rights are selfevidently discoverable from the perspective of natural human practical reason. I have argued that this interpretation can be developed to offer a plausible response to the Ethnocentricity Problem.

I will close by emphasising the modesty of the conclusions that I believe have been reached in this essay. I do not claim that the essay's case for Natural Law Foundationalism is such as to render Metaphysical Foundationalism defunct, or the Ethnocentricity Problem definitively answered. I do not claim that it deflects every forthcoming Functionalist criticism of Functionalism. What I believe I have established in this essay is more modest. Its arguments lay the groundwork for further investigation into these matters by delineating the meaning, shape and direction of Natural Law Foundationalism and displaying its potential and attractiveness. I hope to have shown why Natural Law Foundationalism is a legitimate participant in the contemporary clash between Foundationalism and Functionalism, and why it should be taken more seriously as such. 